() Entomologica Fennica. 12.X.1993

\title{
The Sarcophagidae (Diptera) described by C. De Geer, J. H. S. Siebke, and O. Ringdahl
}

\section{Thomas Pape}

\begin{abstract}
Pape, T. 1993: The Sarcophagidae (Diptera) described by C. De Geer, J. H. S. Siebke, and O. Ringdahl. — Entomol. Fennica 4:143-150.

All species-group taxa described by or assigned to C. De Geer, J.H.S. Siebke, and $\mathrm{O}$. Ringdahl are revised. Musca vivipara minor De Geer, 1776 and Musca vivipara major De Geer, 1776 are considered binary and outside nomenclature. The single species-group name ascribed to Siebke is shown to be unavailable. A lectotype of Sarcophaga verticina Ringdahl, 1945 [= S. pleskei (Rohdendorf, 1937)] is designated and Brachicoma borealis Ringdahl, 1932 is revised and resurrected as a distinct species.
\end{abstract}

Thomas Pape, Zoological Museum, Universitetsparken 15, DK-2100 Copenhagen, Denmark

\section{Introduction}

All Sarcophagidae described by the Scandinavian authors Fabricius, Fallén, and Zetterstedt were treated by Pape (1986), and the single species described by Linnaeus was revised (for the first time!) by Richet (1987). Other Scandinavian authors of taxa in this family include Charles (or Carl) De Geer and Oscar Ringdahl, who have each proposed two species-group names, and it is the purpose of the present paper to revise these taxa and to comment on their identity and availability. Also included is a single species-group name, which has erroneously been credited to J. H. S. Siebke.

\section{Format and depositories}

References are given to published biographies of the authors in question, and biographical notes are included only when they relate directly to the specimens concerned or to the taxonomic decisions made. Original labels of primary type specimens have been cited, with text from different labels separated by semicolons. All lectotypes have been given a red label stating their status as such. Paralectotypes, if any, have been recovered and are discussed separately under the entry 'additional material.'

\section{Results}

\subsection{Charles De Geer (1720-1778)}

Biographical information: Persson et al. (1984).

De Geer (1776) considered only two speciesgroup taxa within the Sarcophagidae, Musca vivipara major and Musca vivipara minor, but apart from Villers (1789:480), who listed a "Vivipara minor", no other author has ever rec- 
ognized De Geer's Sarcophagidae in their original form. Actually, apart from Villers (1789) I have only recovered one other reference to De Geer's sarcophagid taxa, namely the mention of "vivipara (De Geer)" as a junior synonym of Sarcophaga carnaria (Linnaeus) in the catalogue of Bezzi \& Stein (1907:477). This synonymy was repeated in the catalogue of Verves (1986: 181).

Persson et al. (1984) considered all names proposed by De Geer (1776) to be binominal, and where species-group names appeared as two word combinations these were united. As is explained by Thompson \& Pont (in press), these two word combinations do not refer to single entities and joining them thus conflicts with the Code [ICZN: 11 (h) v]. It could be argued that the names were trinomina, but the evidence is little convincing. Especially for De Geer names like Musca minor larvarum and Musca major larvarum, it is evident that De Geer did not propose formal trinomina but descriptive binary names (see Thompson \& Pont (in press) for further discussion of De Geer names). As binary names, Musca vivipara minor and Musca vivipara major have no standing in formal nomenclature as currently defined by the Code. I have, however, given a brief account on what we can deduce on their identity, partly for historical reasons, partly for the convenience of discarding them safely.

\section{vivipara major}

Musca vivipara major De Geer, 1776:63 (vernacular name + description in French on p. 62). Unavailable binary name (and an unnecessary replacement name for Musca carnaria Linnaeus, 1758 [= Sarcophaga carnaria (Linnaeus, 1758)]).

Identity. Persson et al. (1984) argued convincingly that those names, where one or more synonyms were given, should be treated as unnecessary replacement names, thereby avoiding any problems with potential types and availability by subsequent usage. As a replacement name, the identity is tied to the type material of the replaced name, here = Musca carnaria. Accordingly, Musca vivipara major has no type locality [given as "France" by Verves (1986:181) although De Geer made most of his observations at his estate in Leufsta, Sweden, (= Lövsta, $60 \mathrm{~km}$ north of Uppsala) from which locality he most probably obtained his specimens]. The taxon Sarcophaga carnaria was revised by Richet (1987), who designated a lectotype and argued that carnaria is the valid name of the taxon Sarcophaga schulzi Müller (see Povolný \& Verves 1987 for further information on synonymies).

One can only guess which of the common species of Sarcophaga Meigen De Geer had in front of him, but most probably there were more than one. It is evident from the description, drawings and biological notes that De Geer saw a lot of specimens. He obviously did not employ a strict type concept, neither did his contemporaries, and he was in the main more interested in biology than species limits. I have tried to trace the material of Musca vivipara major in the collection of De Geer (Swedish Mus. Nat. Hist., Stockholm), but only a single specimen could be found. It is a female in good condition, with the handwritten label "carnaria", and it belongs to Sarcophaga in the broad sense used by Downes (1965) and Pape (1988). I have been unable to identify the specimen, but it does not match any species known from Scandinavia. Actually, the possibility exists that De Geer received this specimen from abroad, at least he states that specimens of Musca vivipara major "se trouvent également en Pensylvanie" (p. 69). On the other hand, there is no evidence or indication that it could not be a later addition, and as it has no significance for the nomenclatoral decisions and little, if any, significance for the interpretation of De Geer's original concept of his Musca vivipara major, I will not discuss it further. We have, however, one important clue to the identity of at least one of the specimens definitely seen by De Geer: His illustration of the male terminalia (Fig. 1). This is interesting and deserves proper mention as the figure represents the first published observation of the clasping and intromittent structures in the Sarcophagidae. These structures were more than a century later recognized as the sine qua non for a reliable identification. De Geer suggested tentatively that this structure could "caracterise le sexe", and his description runs as follows: "il y a une longue partie écailleuse tréssinguliere, divisée en quelques articles \& garnie au bout de plusieurs pointes écailleuses un peu 

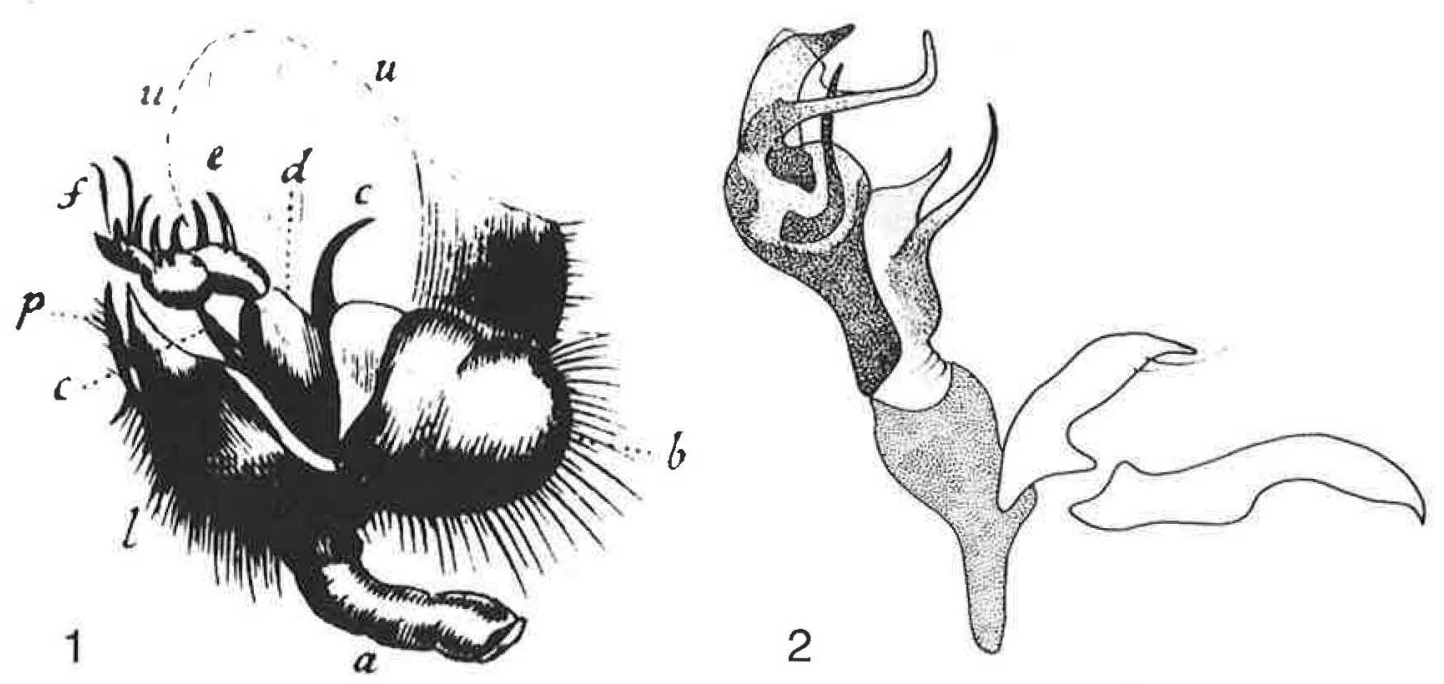

Fig. 1-2. Sarcophaga similis, male terminalia. - 1: complete terminalia, from De Geer (1776). - 2: phallus and gonocoxite + gonocoxital lobe, from Pape (1987).

courbées" (p. 69). Considering the rather few Sarcophaginae, which are known from central Sweden (Pape 1987b), the figure leaves no doubt that the specimen examined and illustrated by De Geer was a male of Sarcophaga similis Meade, 1876 (compare Figs. 1, 2).

\section{vivipara minor}

Musca vivipara minor De Geer, 1776:70. Sweden. Unavailable binary name.

Identity. I have been unable to recover any original specimens in De Geer's collection, and the identity - or more probably identities — can only be an informed guess comparing De Geer's biological information with current knowledge of which species are common in southern and central Sweden. There is no doubt that De Geer's species concept was based on a fairly large number of specimens, some of which were dissected while others were observed in nature and never collected. Whether or not one or a few type specimens may be recovered from his collection or from any other source, we will never be able to trace the actual number of specimens (and species) involved. The original description gives few clues as "cette Mouche [= Musca vivipara minor $]$ est si semblable à la précedente [= Musca vivipara major], tant en figure qu'en couleurs, qu'une même déscription convient absolument à toutes les deux" (p. 70), and the only diagnostic feature given by De Geer to separate this species from the similar Musca vivipara major is its smaller size ("la moitié plus petite que l'autre [= Musca vivipara major]" p. 71). Size alone is generally a poor indicator of specific assignment, and especially so in the genus Sarcophaga, where size ranges of species are usually broadly overlapping. A restricted larval food source will produce strongly undersized specimens, and the smallest individuals of a species are often less than half the length of the largest.

Large numbers of specimens of Sarcophaga s.str. (= Sarcophaga of Pape 1987b) is a very characteristic element of the fauna of Sarcophaginae in rural and suburban biotopes in central 
and northern Europe (Draber-Monko 1985). Thus, it is reasonable to assume that De Geer's concept of Musca vivipara minor included one or more species of Sarcophaga s.str., of which four are known from Uppland, the faunal district containing Lövsta: S. carnaria (Linnaeus), S. lasiostyla Macquart, S. subvicina Rohdendorf and $S$. variegata (Scopoli). Note that $S$. lasiostyla was only recently recorded from this district by Hedström (1988), although it seems to be fairly abundant. As the oldest specimen of S. lasiostyla reported by Hedström was caught before 1946 (exact date not given), presence of this species in Uppland is probably not a recent range extension. For Southern and Central Sweden, S. variegata outnumbers any other species of Sarcophaga s.str. in museum collections, and it seems likely that this species was abundant on De Geer's estate and actually was observed, if not collected, by De Geer. Listing Musca vivipara minor under the older name Sarcophaga variegata thus rests on sound arguments and is herewith recommended.

Additional material. An attempt to recover any original specimens of Musca vivipara minor in the De Geer collection produced only an unlabeled female of Pollenia vagabunda (Meigen), Calliphoridae, (K. Rognes det.). The description leaves no doubt, however, that the species concerned, whether one or - more probable several, should be assigned to the Sarcophagidae. De Geer stressed the practically identical appearance to Musca vivipara major, as already mentioned. Moreover, he dissected several females with mature larvae, and these all had "le derriere garni d'une cavité en forme de bourse, dont les bords ont une couronne de mamelons charnus, \& au fond de laquelle se trouvent les deux plaques circulaires, qui sont garnies chacune de trois stigmates jaunatres en forme de boutonnieres". Undoubtedly sarcophagid larvae. Some of these larvae were reared to maturity on meat ("de la viande"). Considering the sparse Scandinavian fauna, this information settles beyond any doubt that De Geer referred to specimens of the subfamily Sarcophaginae, and it is equally certain that these specimens belonged to the genus Sarcophaga sensu lato (= tribe Sarcophagini of Pape 1987b). The only other Sarcophaginae are the grasshopper parasitizing Blaesoxipha spp. and the coprophagous Ravinia pernix (Harris).
Remarks. Two unlabeled female Sarcophagidae in the De Geer collection were found standing under the name Musca minor larvarum De Geer, 1776:25. They are identified by me as Sarcophaga sp. and Sarcophaga (Helicophagella) melanura Meigen, 1824 respectively. They do not, however, represent syntypic material of Musca minor larvarum as they do not fit the original description. Also, De Geer's (1776:26) description evidently is a species of Tachinidae: "Elles [= the flies] vivent également, sous la forme de larves, dans le corps de chenilles."

\subsection{Johan Heinrich Spalkhawer Siebke (1816- 1875)}

Biographical information: Schneider 1876, SootRyen 1942:5-6, Natvig 1944:22-25.

After Siebke's death, his insect collection was acquired by the University of Oslo and it is now kept separately in the Zoological Museum, each specimen being labeled with an individual number. Sparre Schneider arranged for publication of the posthumous edition of Siebke's 'Fauna norvegica Insectorum' (1877), and he may possibly have worked actively on the collection. In the following years, conservator W. M. Schøyen curated and labeled the specimens, and further reorganizations or modifications of Siebke's original arrangement may have occurred, at least the collection contains specimens not listed in Siebke (1877) while others appear to have disappeared (K. Rognes, in litt.). Therefore, there is no guarantee that the collection in its present state reflects Siebke's own concepts of the species.

Siebke is generally considered to have proposed a single name within the Sarcophagidae, and like the names of De Geer, it has mostly been overlooked and has never been recognized in its original form. Both Bezzi \& Stein (1907: 491) and Verves $(1986: 134)$ cite the name 'Sarcophaga nova' from Siebke's (1877) 'Catalogus dipterorum Norvegiae' of his 'Fauna norvegica Insectorum' and they treat it as a junior synonym of Ravinia striata (Fabricius) [preocc., = Ravinia pernix (Harris)]. Siebke (1877:94) actually lists a "Var. nova (m)" under his Sarcophaga striata, and he gives a diagnosis and the 
data "Østerdalia 5 Aug. 1870", probably referring to a single male. If one checks the report on his collecting trip to the valley Österdalen (Siebke 1872:50, 1873:88), one will find no variety of Sarcophaga striata but a "Var nova, mas." under Sarcophaga cruentata, with identical date + locality and an identical diagnosis (only differing in punctuation and in the spelling of a single word). Most probably the same specimen is involved, but no specimen in the Siebke collection is labeled accordingly ( $\mathrm{K}$. Rognes, in litt.). There can be no doubt, however, that Siebke (1872, 1873) did not intend to propose the formal name "nova" for this variety. From his Österdal-material, he proposed a total of 13 varieties of insects already named by previous authors and all fully diagnosed and stated to be "nova", but with no proposal of new (subspecific) species-group names. That Siebke used "nova" simply to designate the variety as new (i.e., not previously known) is especially clear in his entry for "Echinomyia Marklini Zett." (1872:49, 1873:87), where he lists a "Var. b (nova)" and a "Var. c (nova)". The name "Sarcophaga nova Siebke" obviously has never been proposed and is therefore unavailable.

\subsection{Oscar Ringdahl (1885-1966)}

Biographical information: Lindroth $(1955,1966)$.

\section{borealis}

Brachycoma borealis Ringdahl, 1932:21. Lectotype or, designated by Verves (1982:290), Finland: Lapponia enontekiensis, Malla, R. Frey (Zool. Mus., Univ. Helsinki, Finland). Terminalia dissected by me and glued to a piece of cardboard pinned with the specimen. Lectotype otherwise in perfect condition.

Labels. Malla; R. Frey; 1135; Mus.Zool.Helsinki Loan No. D 5595; Brachycoma borealis Ringd. n.sp.

Identity. Brachicoma borealis Ringdahl, 1932, as correctly recognized by Verves (1982). Note that Brachycoma is an erroneous subsequent spelling of Brachicoma Rondani. Some disagreement has existed on whether or not to give borealis specific rank. Ringdahl himself treated borealis as a distinct species in several later publications (1937, 1945b), but seemingly changed his mind and lowered the taxon to subspecific level of B. devia (Fallén, 1810) in Ringdahl (1944) and in his 'catalogus insectorum' (1952). Verves $(1982$, 1984) treated $B$. borealis as a distinct species while Pape (1987a,b) followed Ringdahl (1952) by including borealis as a junior synonym of $B$. devia. I have examined the terminalia of the male lectotype, and their morphology strongly corroborates a status as a distinct species and confirm the conspecificity with specimens from Russia (Murmansk) examined and illustrated by Verves (1982). Illustrations supporting the present decision are given in Figs. 3-10.

Additional material. Ringdahl (1932) does not give any particular specimen as the type: " $10^{\prime}$ von Frey bei Malla, 1Q von Hellén bei Ponoj gefangen" (p. 21). These specimens are listed as "Holotypus und Paratypus" by Verves (1982:290) who moreover gives "Terra typica: Malla", thereby effectively designating the male collected by Frey as lectotype. The female from Ponoj [probably the town Ponoj (or Ponoi) near the mouth of the river Ponoj, Kola Peninsula, Russia] automatically becomes a paralectotype; I have identified it as Brachicoma devia (deposited in Zool. Mus., Helsinki). However, Ringdahl apparently based his species concept on a more extensive material: "In Schweden habe ich die Art in dem nördlichsten Lappland bei Abisko und Vassijaure und in dem westlichen Jämtland bei Storlien getroffen (regio alpina und subalpina)". These specimens were obviously considered conspecific and they are thus all syntypes [ICZN: 72(b)(i)]. I have examined all specimens of Brachicoma from the Ringdahl collection (Mus. Zool., Univ. Lund, Sweden) and seven specimens could be recovered from the three above-mentioned localities: 10, Abisko 12. vii.1918; 1ㅇ, Abisko 4.vii.1922; 107, Abisko 8.vii.1922; 10, Vassijaure, 14.vii.1918; 10, Vassijaure 5.vii.1937; 1o, Storlien 12.vii.1914; 1우, Storlien 25.vi.1934 [all dates handwritten, locality names in violet print]. These specimens are all Brachicoma borealis, but obviously only the five specimens caught before publication of the name in 1932 can be part of Ringdahl's original material. With the lectotype designation in Verves 1982, the pre-1932 specimens are automatically designated as paralectotypes [ICZN: 74(a)(iv)] and I have labeled them accordingly. 

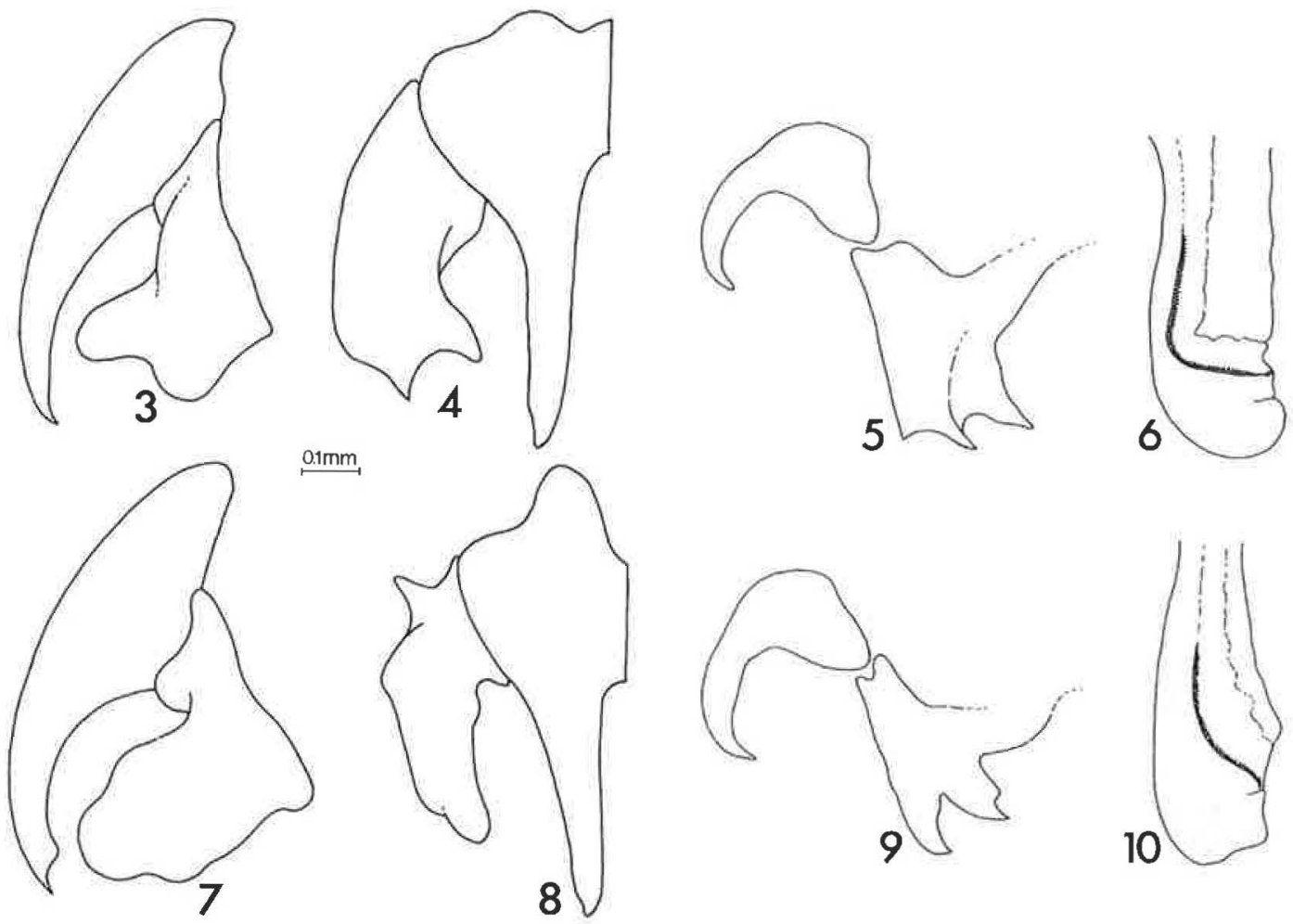

Fig. 3-10. Brachicoma spp., male terminalia. 3-6, Brachicoma devia. 7-10, Brachicoma borealis. - 3, 7: Right cercus and surstylus, vestiture omitted, lateral view. $-4,8$ : Left cercus and surstylus, vestiture omitted, posterior view. $-5,9$ : Right gonocoxital lobe + gonocoxite, lateral view. $-6,10$ : Distiphallus, right lateral view.

With the resurrection of $B$. borealis as a distinct species, the distributional records in Pape $1987 \mathrm{~b}$ had to be re-checked. In Sweden, B. borealis is known from Abisko (Torne Lappmark) and Storlien (Jämtland), with B. devia ocurring sympatrically in the latter province (although it remains to be seen whether any habitat segregation exists). The record of $B$. devia from Jokkmokk (Lule Lapmark) in Engelmark \& Engelmark (1989) has been checked and is herewith confirmed. In Finland, B. borealis is known from the type locality Malla (Lapponia enontekiensis), other records in Pape (1987b) being B. devia. Only $B$. devia has been recorded from Norway. The record of $B$. borealis from Vuorje (Finnmark) in Ringdahl (1944) was discussed by Rognes (1986), who preferred to treat the specimen in question as $B$. devia. I have examined the specimen and agree with Rognes in identifying it as $B$. devia.

\section{verticina}

Sarcophaga tuberosa ssp. verticina Ringdahl, 1945a:35. Lectotype $O^{\prime}$, herewith designated, Sweden: Torne Lappmark, Abisko, 27.vii.1926, O. Ringdahl (Mus. Zool, Univ. Lund, Sweden). The lectotype is in good condition, with the terminalia extended.

Labels. Abisko 27.7-26; Sarcophaga tuberosa Pand.; 1983 610 [= a loan tag]; Parasarcophaga pleskei Rod., 1937 K. Rognes det. 1983.

Identity. Sarcophaga (Liosarcophaga) pleskei (Rohdendorf, 1937), as correctly, although tentatively, proposed by Rognes (1986:13), who assigned the species to the genus Parasarcophaga Johnston \& Tiegs.

Additional material. Ringdahl (1945a:35) does not specify the number of specimens studied nor does he give any exact localities. He just states that his diagnostic characters are valid for 
"all specimens [of S. tuberosa sensu Ringdahl] known by me from the fjeld ravines" [my translation from Swedish]. The following specimens were standing in Ringdahl's collection (Mus. Zool., Univ. Lund) at the label "Sarcophaga tuberosa ssp. verticina": $10^{7}$, data as lectotype; $10^{7}$, data as lectotype but with the date " $6 .-7-$ 22"; 10", "Jebrenj. 22.7-26". All have been labeled by me as paralectotypes, and all $=S$. pleskei as correctly identified by Rognes (1986). Ringdahl's concept of the nominal form of $S$. tuberosa Pandellé is a misidentification of $S$. (Liosarcophaga) portschinskyi (Rohdendorf), which may have misled Verves $(1986: 168)$ to list $S$. verticina as a junior synonym of Parasarcophaga (Liosarcophaga) portschinskyi and give the type locality as "South Sweden".

Acknowledgements. I extend my most cordial thanks to P. I. Persson, Stockholm, R. Danielsson, Lund, B. Lindeberg, Helsinki, A. Fjellberg, 'Iromsö, R. Engelmark, Umeå and Yu. G. Verves, Kiev, for their efforts in sorting out material and making various loan arrangements. K. Rognes, Stavanger, generously sent me extensive information on the Siebke collection and A. C. Pont, Reading (England), made some valuable comments on the De Geer names. V. Michelsen, Copenhagen, provided a thorough critique of an early draft of the manuscript and his suggestions are much appreciated. Part of this study was supported by grant no. 11-6152 from the Danish Natural Science Research Council.

\section{References}

Bezzi, M. \& Stein, P. 1907: Katalog der paläarktischen Dipteren. III. Cyclorrhapha Aschiza. Cyclorrhapha Schizophora: Schizometopa. - Budapest. 828 pp.

De Geer, C. 1776: Mémoires pour servir à 1'histoire des insectes. Vol. 6. - Stockholm. 523 pp, 30 pls.

Downes, W. L., Jr. 1965: Family Sarcophagidae. - In: Stone, A. et al. (eds.): A catalog of the Diptera of America north of Mexico. U.S. Dept. Agric., Agric. Handbook 276:933-961.

Draber-Monko, A. 1985: Parasitoids of earthworms of the genera Pollenia R.-D. and Sarcophaga Meig. in the urban green of Warsaw and in some habitats of the Mazovian Lowlands. - Fragm. Faun. 29:311-375.

Engelmark, R. \& Engelmark, T.-B. 1989: The calyptrate fly fauna (Diptera, Calyptratae) of three fens near Jokkmokk in Swedish Lapland. (In Swedish with English abstract) - Entomol. Tidskr. 110:81-95.

Hedström, L. 1988: Swedish insect records - report 4. (In
Swedish with English abstract) - Entomol. Tidskr. 109:139-149.

Lindroth, C. 1955: [Oscar Ringdahl 70 years June 23rd 1955]. (In Swedish) — Opusc. Entomol. 20(2-3):9798.

- 1966: Oscar Ringdahl - In memoriam. (In Swedish.) — Opusc. Entomol. 31(1-2):118.

Natvig, L. R. 1944: [Entomology at the Royal Frederik's University. A contribution to the history of Norwegian entomology.] (In Norwegian) - Norsk Entomol. Tidsskr. 7:1-73.

Pape, T. 1986: A revision of the Sarcophagidae (Diptera) described by J.C. Fabricius, C.F. Fallén, and J.W. Zetterstedt. - Entomol. Scand. 17:301-312.

- 1987a: An annotated check-list of Finnish flesh-flies (Diptera: Sarcophagidae). — Notulae Entomol. 67:4346.

- 1987b: The Sarcophagidae (Diptera) of Fennoscandia and Denmark. - Fauna Entomol. Scand. 19:1-203, 2 pl. Leiden \& Copenhagen.

- 1988: A revision of the Palaearctic Sarcophagidae (Diptera) described by C. Rondani, - Stuttg. Beitr. Naturk. (Ser, A) 416:1-22.

Persson, P. I., Pont, A. C. \& Michelsen, V. 1984: Notes on the insect collection of Charles De Geer, with a revision of his species of Fanniidae, Anthomyiidae and Muscidae (Diptera). - Entomol. Scand. 15:89-95.

Povolný, D. \& Verves, Yu. G. 1987: Revision der paläarktischen Arten der Gattung Sarcophaga Meigen, 1828 [sic!] (Diptera, Sarcophagidae). - Acta Entomol. Mus. Nat. Prag. 42:89-147.

Richet, R. 1987: L'identité de la "mouche à damier" Sarcophaga carnaria (Linné, 1758) [Dipt. Satcophagidae]. - Bull. Soc. Entomol. France 91(3-4):131-135.

Ringdahl, O. 1932: Eine neue Brachycoma-Art. - Notulae Entomol. 12:21.

- 1937: [Contributions to the knowledge of the distribution of Swedish tachinids.] (In Swedish) - Entomol. Tidskr. 58:31-38.

- 1944: Contributions to the knowledge of the tachinids and muscids of Norway. - Tromsö Mus. Aarsh. 65(4): 1-27.

- 1945a: [List of the tachinids described by Zetterstedt in Insecta Lapponica and Diptera Scandinaviae, with synonyms and notes on a few species.] (In Swedish) - Opusc. Entomol. 10:26-35.

_ 1945b: [Survey of the species of the family Tachinidae (Diptera) so far known from Sweden.] (In Swedish) —Entomol. Tidskr. 66:177-210.

- 1952: Catalogus insectorum sueciae. XI. Diptera Cyclorrhapha: Muscaria Schizometopa. - Opusc. Entomol. 17:129-186, 1 map.

Rognes, K. 1986: The Sarcophagidae (Diptera) of Norway. - Fauna Norv. B 33: 1-26.

Schneider, J. S. 1876: Nécrologe de Mr. I.H.S. Siebke. In: Schneider, J. S. (ed.), Enumeratio insectorum norvegicorum. III, catalogum lepidopterorum continentem: vii-x. A.W. Brøgger, Christiania [= Oslo]. 
Siebke, J. H. S. 1872: [Contributions to the insect fauna of Norway. Report on a journey to Østerdalen in 1870.] (In Norwegian) - J. Dahl, Christiania [= Oslo]. 64 pp. [This is identical to Siebke (1873) except for the pagination and the cover, and it was published by the same publisher. It is, however, explicitly stated to have been issued in 1872 as a report for the University of Oslo.]

- 1873: [Contributions to the insect fauna of Norway. Report on a journey to Østerdalen in 1870.] (In Norwegian) - Nyt Mag. Naturv. 19:39-102.

- 1877: Catalogus dipterorum norvegiae. - In: Schneider, J. S. (ed.), Enumeratio insectorum norvegicorum. IV, catalogum dipterorum continentem: ix-xiv +255 pp. A.W. Brǿgger, Christiania [= Oslo].

Soot-Ryen, T. 1942: A review of the literature on Norwegian Diptera until the year 1940. - Tromsø Mus. Aarsh. 65(3):3-46.
Thompson, F. C. \& Pont, A. C. in press: Catalogue of Musca-names. - Theses Zoologicae.

Verves, Yu. G. 1982: 64h. Sarcophaginae. - In: Lindner, E. (ed.), Die Fliegen der palaearktischen Region 327: 235-296.

- 1984: The food connections of the Palaerctic (sic!) Sarcophagidae (Diptera) with bees (Apoidea, Hymenoptera). — Trudy Zool. Inst., Leningrad 128:53-63.

- 1986: Family Sarcophagidae. - In: Soós, A. \& Papp, L. (eds.), Catalogue of Palaearctic Diptera 12, Calliphoridae-Sarcophagidae: 58-193. Akadémia Kiadó, Budapest.

Villers, C. 1789: Caroli Linnaei entomologia, faunae suecicae descriptionibus aucta. Vol. 3. 657 pp., 4 pls. - Lugduni [= Lyon].

Received 13.IX.1992 